Supporting Information

\title{
Palladium Nanosheet-Based Dual Gas Sensors for Sensitive Room Temperature Hydrogen and Carbon Monoxide Detection
}

Abhishek Kumar, ${ }^{a}$ Yaoli Zhao, ${ }^{a}$ Mohammad Moein Mohammadi, ${ }^{a}$ Jun Liu, ${ }^{\mathrm{b}, \mathrm{c}}$ Thomas Thundat, ${ }^{\mathrm{a}, \mathrm{c}}$ and Mark T. Swihart ${ }^{\mathrm{a}, \mathrm{c}^{*}}$

a Department of Chemical and Biological Engineering, University at Buffalo (SUNY), Buffalo, New York, USA, 14260

${ }^{b}$ Department of Mechanical and Aerospace Engineering, University at Buffalo (SUNY), Buffalo, New York, USA, 14260

${ }^{c}$ RENEW Institute, University at Buffalo (SUNY), Buffalo, New York, USA, 14260

"Corresponding author: swihart@buffalo.edu 


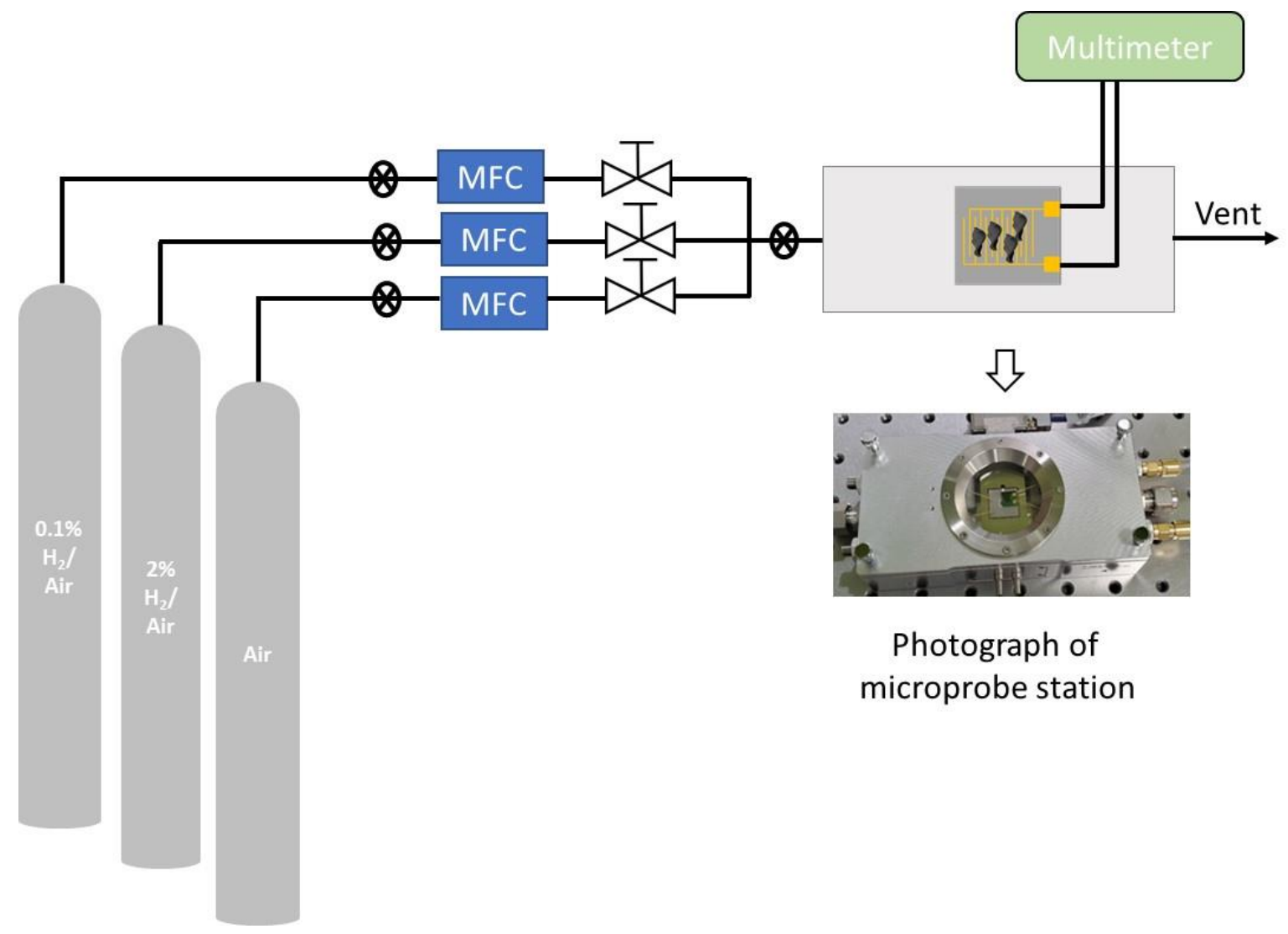

Figure S1: Schematic of gas sensing apparatus. Inset shows a photo of the microprobe station.

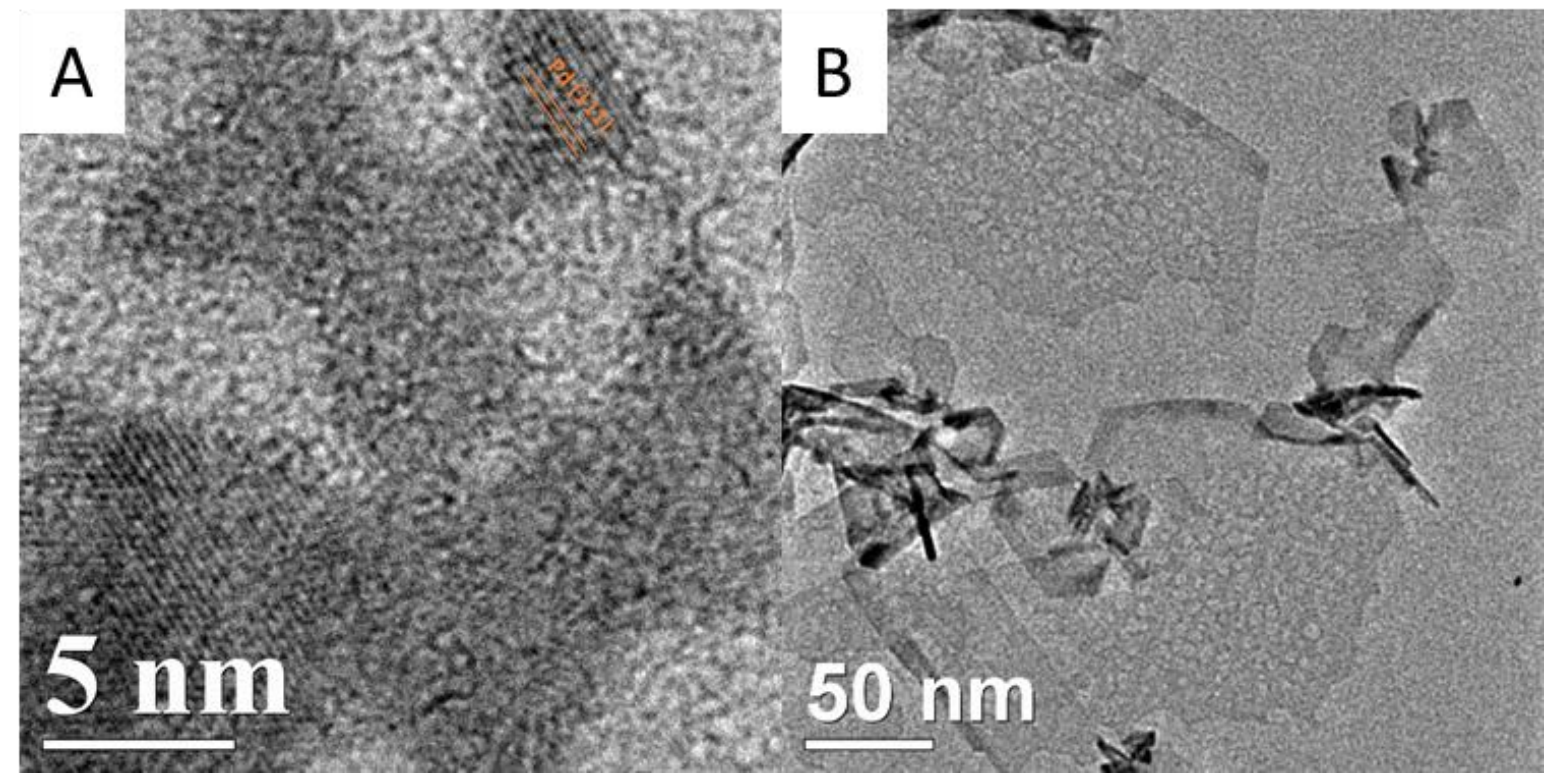

Figure S2: (A) HRTEM, and (B) TEM image of PdNS. 

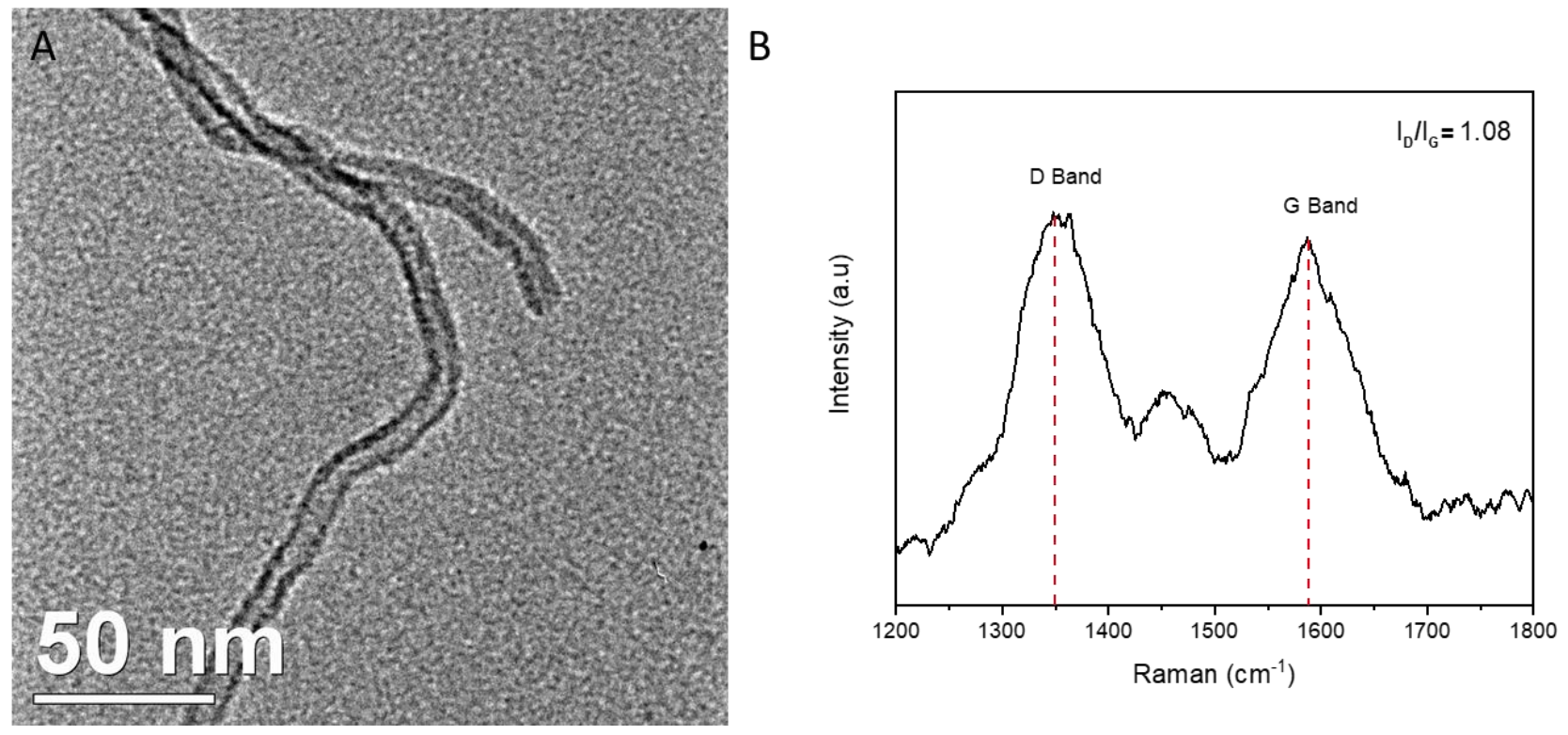

Figure S3: A) TEM image of pristine MWCNT; B) Raman spectrum of pristine MWCNT

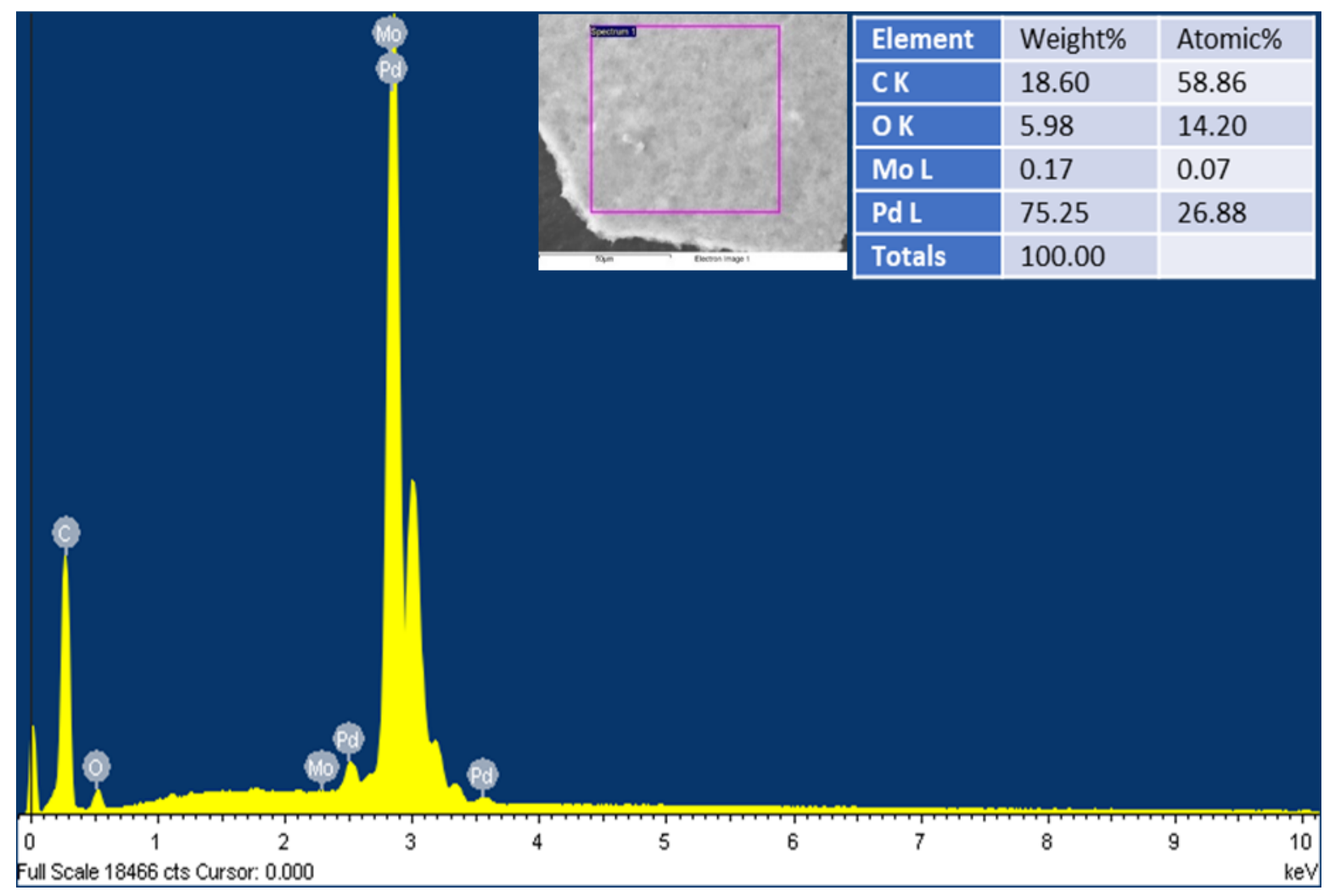

Figure S4: EDS spectrum of Pd nanosheets. The sample was deposited on carbon tape, which contributes to the $\mathrm{C}$ and $\mathrm{O}$ signals. 
A

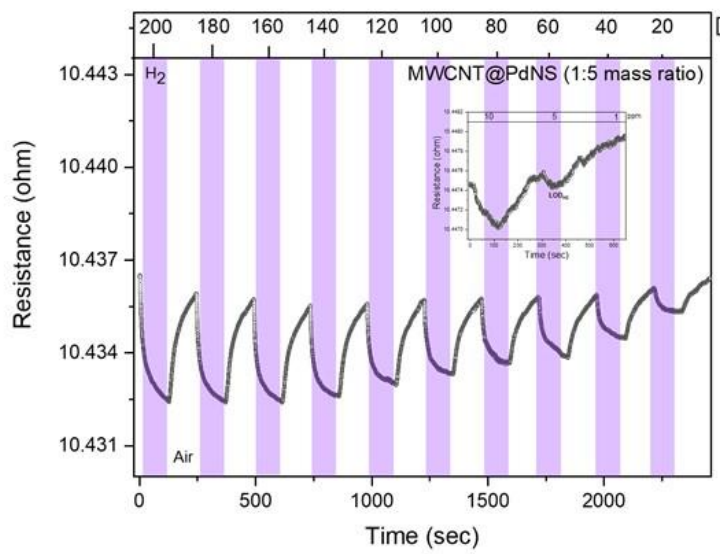

B

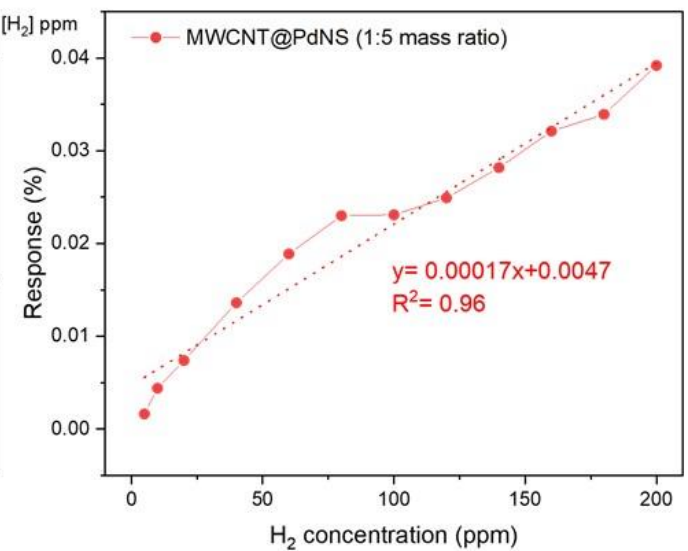

Figure S5: A) Response vs $\mathrm{H}_{2}$ concentration plot for MWCNT@PdNS (1:5 mass ratio). Insets in $A$ shows response of the sensor to lower $\mathrm{H}_{2}$ concentrations (10-1 ppm). Dashed lines in $\mathrm{B}$ is the best linear fit corresponding to the equation presented in the inset. Shaded regions in A indicate times when $\mathrm{H}_{2}$ gas was flowing, at the concentrations indicated at the top of the graphs. Pure air flowed during the unshaded times.
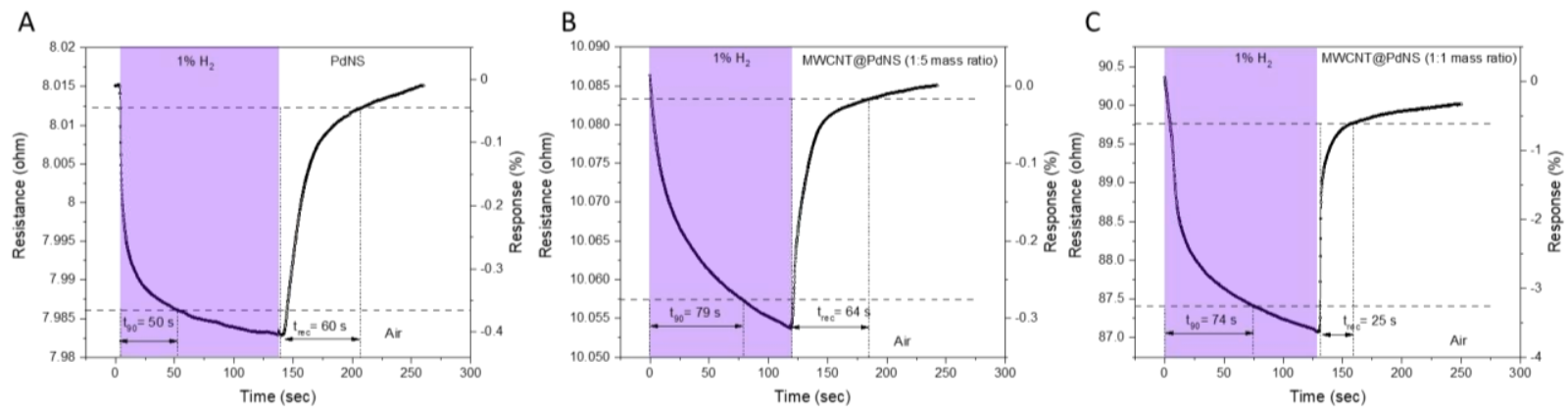

Figure S6: Response, response time and recovery times evaluation of A) PdNS; B) MWCNT@PdNS (1:5 mass ratio); C) MWCNT@PdNS (1:1 mass ratio).

Table S1: Sensing parameter comparison of PdNS and MWCNT@PdNS nanocomposite

\begin{tabular}{|c|c|c|c|}
\hline Material & Response (\%) & Response time (s) & Recovery time (s) \\
\hline PdNS & -0.4 & 50 & 60 \\
MWCNT@PdNS (1:5) & -0.32 & 79 & 64 \\
MWCNT@PdNS (1:1) & -3.6 & 74 & 25 \\
\hline
\end{tabular}



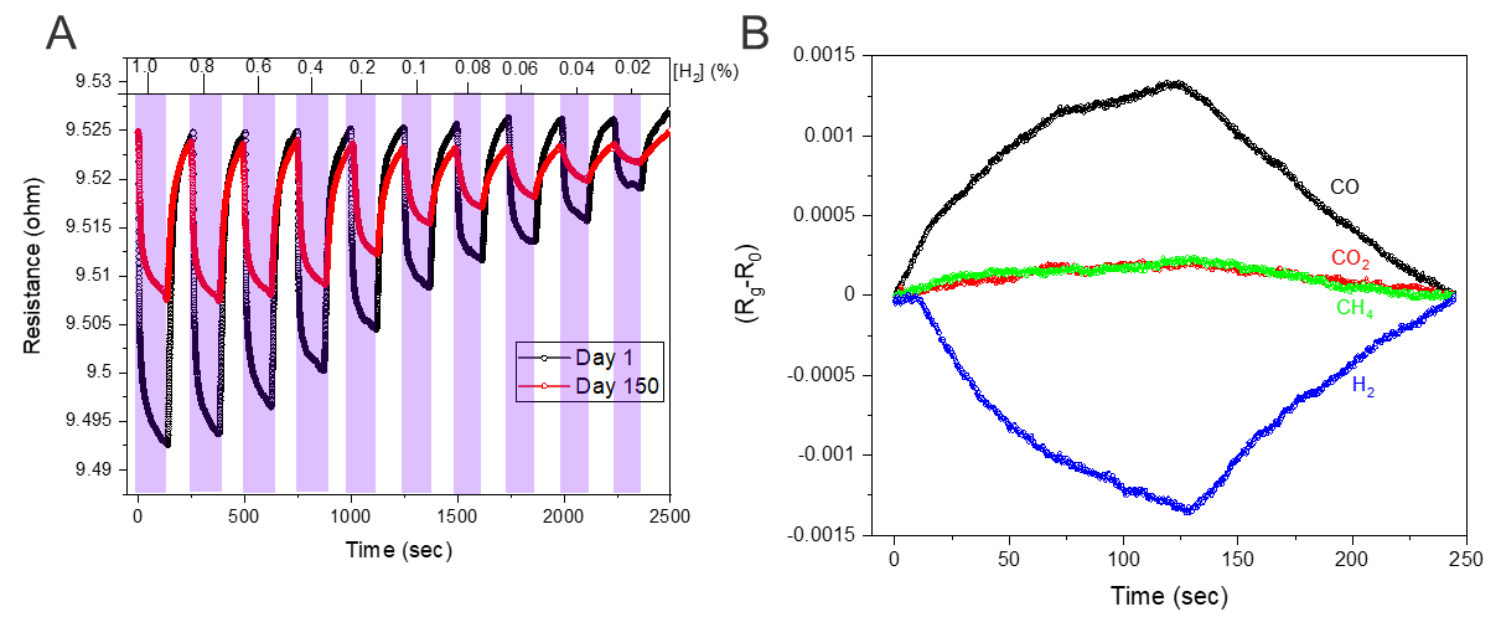

Figure S7: A) Comparison of $\mathrm{H}_{2}$ sensing performance of PdNS sensor on day 1 vs day 150;

B) Response and recovery of PdNS to exposure to $100 \mathrm{ppm}$ of $\mathrm{H}_{2}, \mathrm{CO}, \mathrm{CH}_{4}$, or $\mathrm{CO}_{2}$ in air.

A

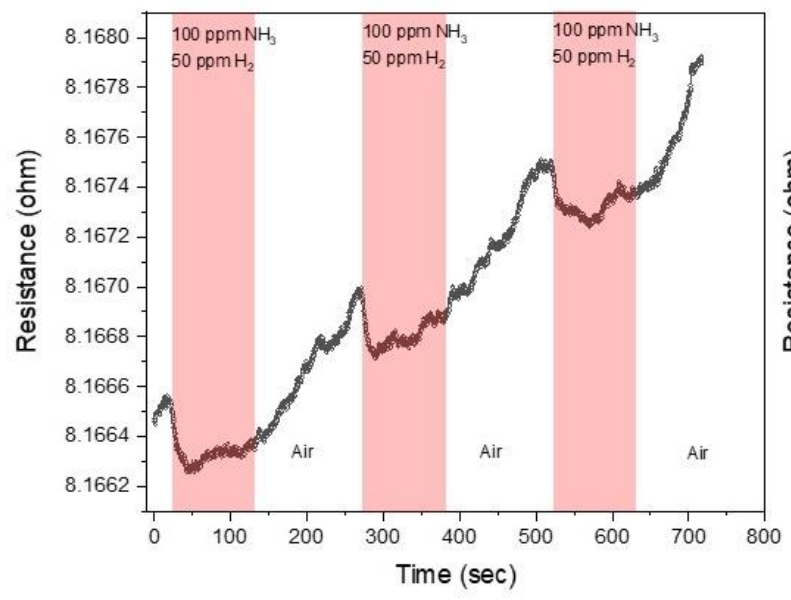

B

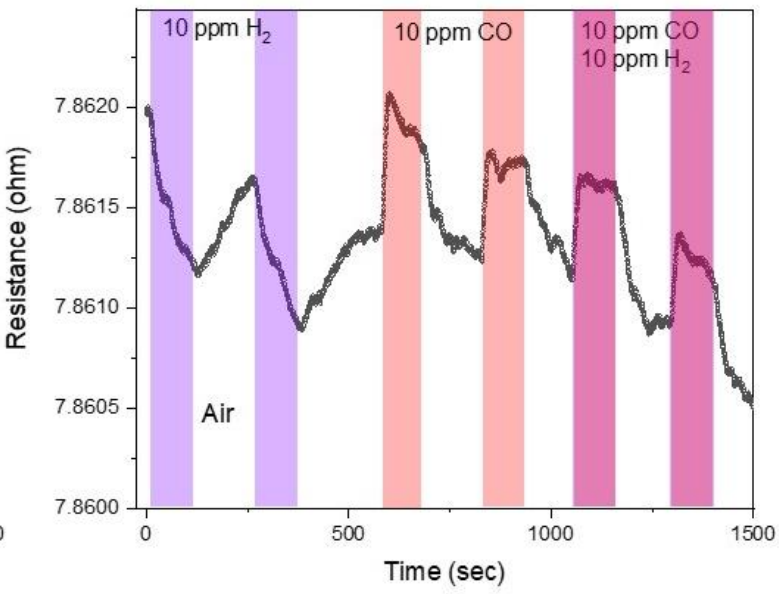

Figure S8: Real-time resistance change of PdNS sensor to (A) $100 \mathrm{ppm}$ of $\mathrm{NH}_{3}$ and $50 \mathrm{ppm}$ of $\mathrm{H}_{2}$; (B) 10 ppm $\mathrm{H}_{2}, 10$ ppm $\mathrm{CO}$, and a mixture containing 10 ppm each of $\mathrm{CO}$ and $\mathrm{H}_{2}$. 

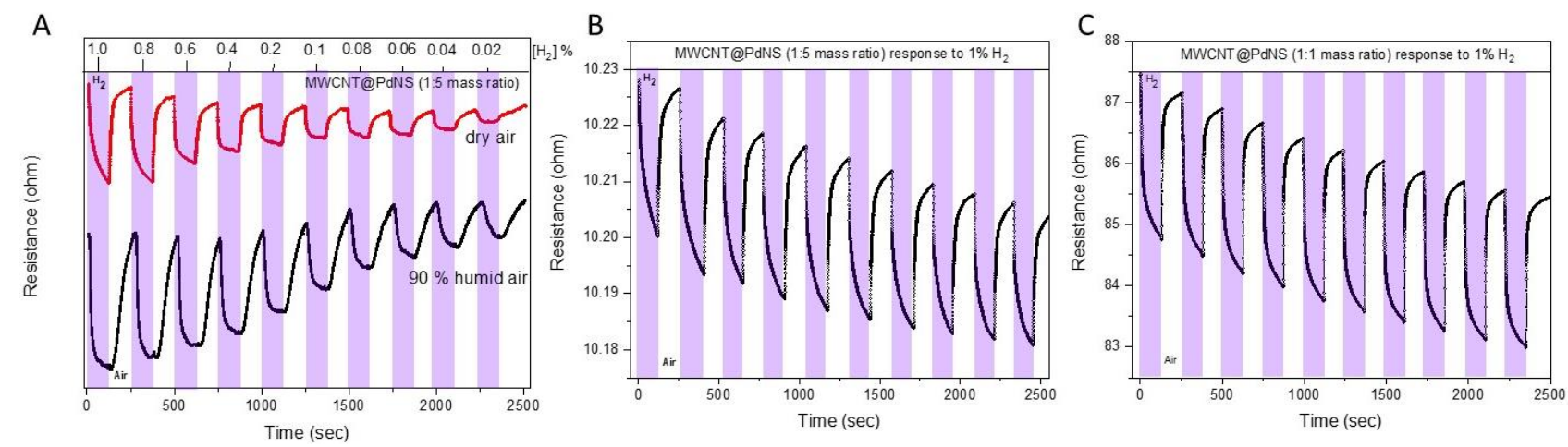

Figure S9: A) Comparison of the normalized response of MWCNT@PdNS (1:5 mass ratio) sensor in dry air and humid air; B) Response of MWCNT@PdNS (1:5 mass ratio) sensor to repeated exposure to $\left.1 \% \mathrm{H}_{2} ; \mathrm{C}\right)$ Response of MWCNT@PdNS (1:1 mass ratio) sensor to repeated exposure to $1 \% \mathrm{H}_{2}$.
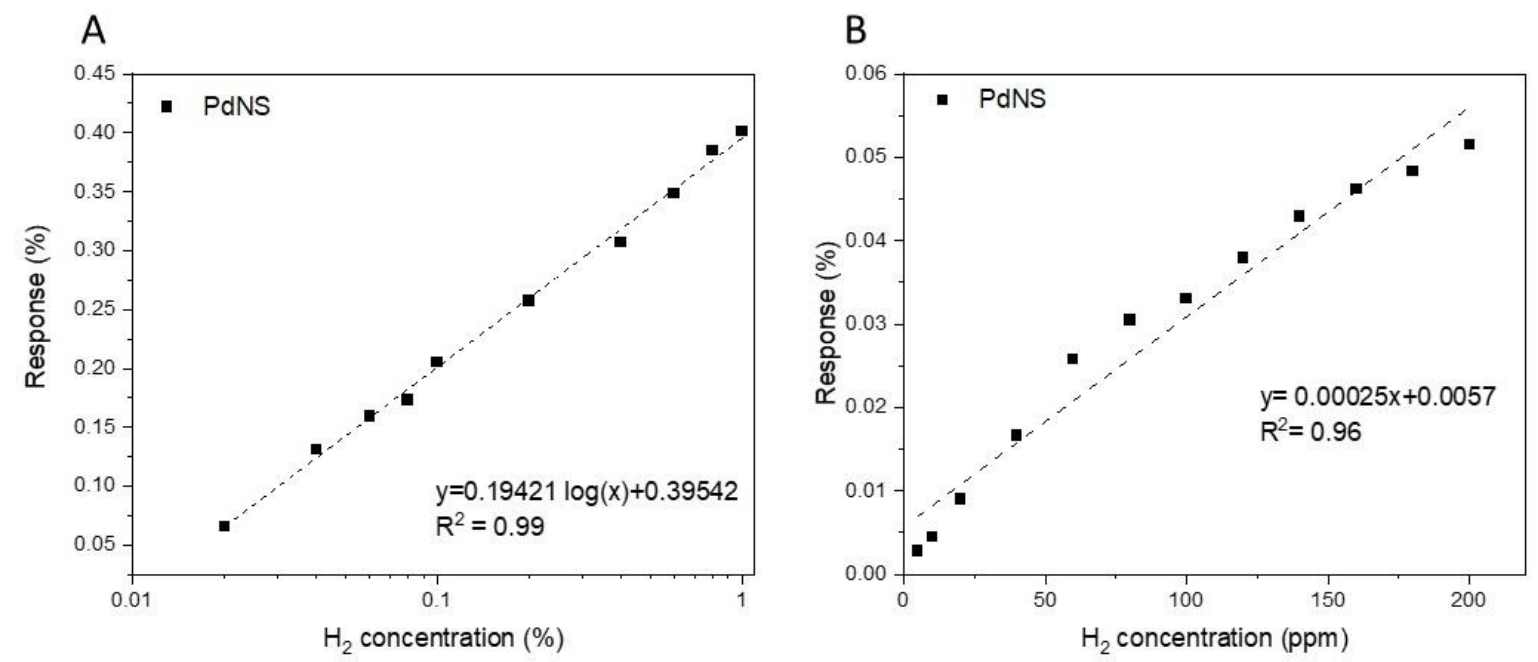

Figure S10: Response vs $\mathrm{H}_{2}$ concentration plot for PdNS to A) (1-0.02\%) $\mathrm{H}_{2}$ in air, B) (2005) ppm $\mathrm{H}_{2}$ in air. Dashed line is best fit corresponding to the equation presented in the inset. 

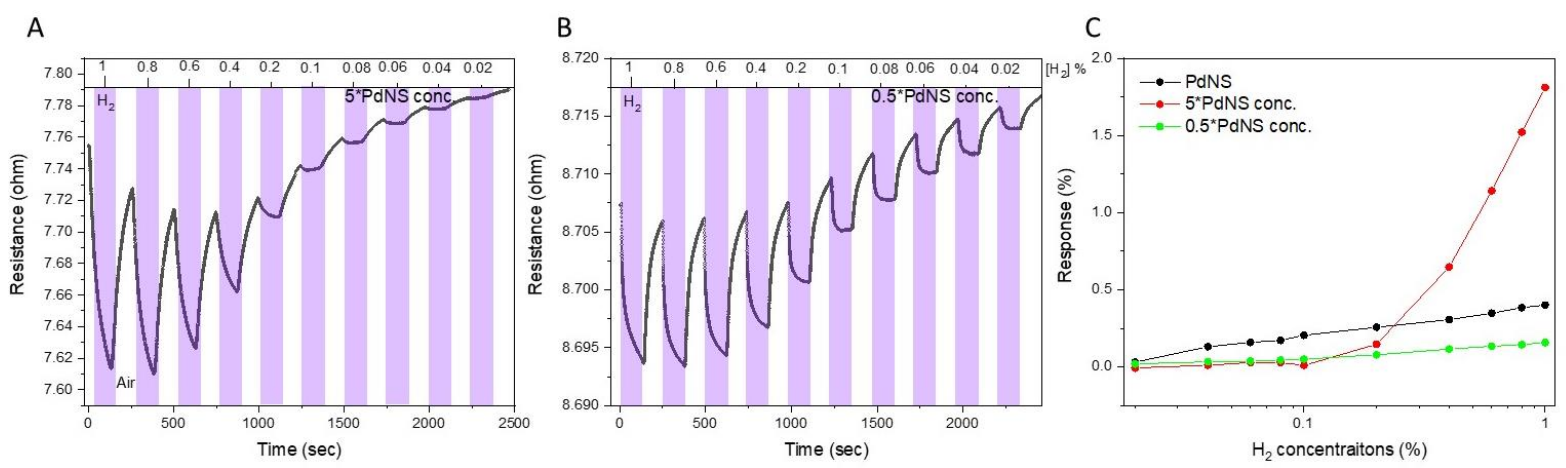

Figure S11: Dynamic $\mathrm{H}_{2}$ sensing performance of sensor with (A) $5^{*}$ PdNS concentration; (B) $0.5^{*}$ PdNS concentration; (C) Comparison of response of PdNS sensor with different concentrations of PdNS.

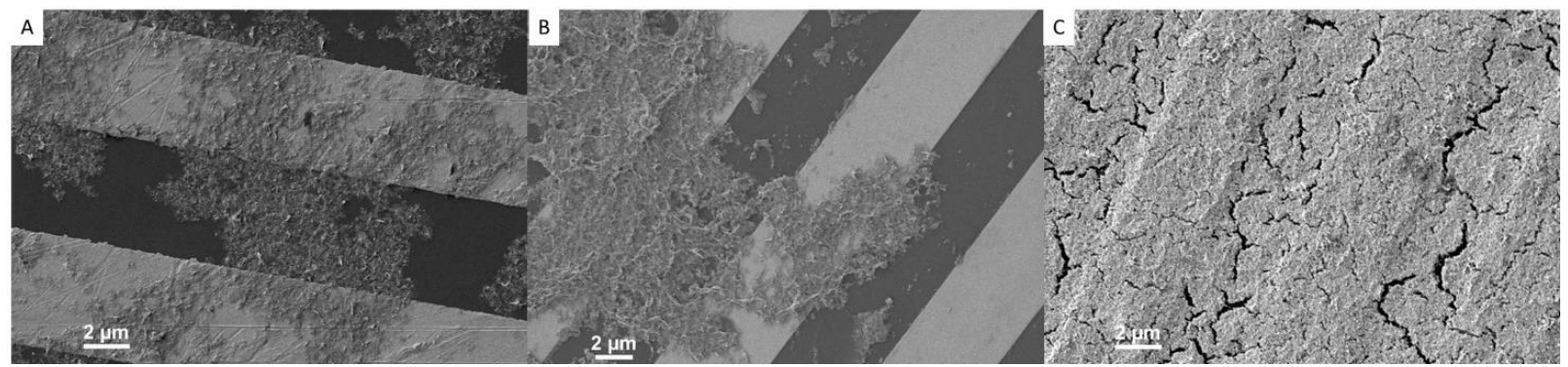

Figure S12: SEM image of PdNS sensor after stability tests with A) $0.5^{\star} P d N S$ conc., B) PdNS,

C) 5*PdNS conc.
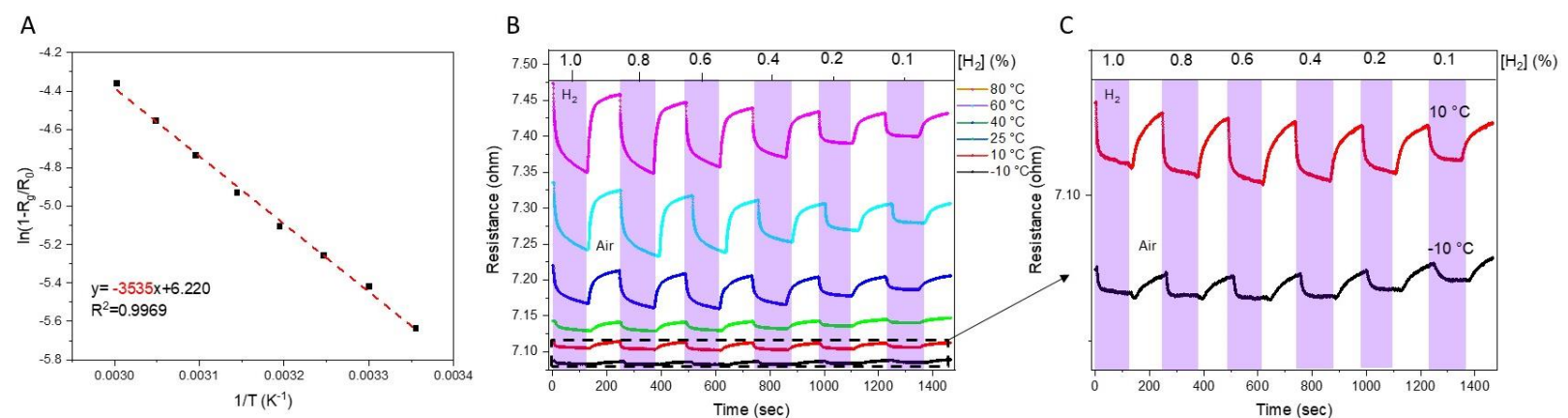

Figure S13: A) Arrhenius plot for resistance change of PdNS sensor with temperature to $1 \%$ $\mathrm{H}_{2}$. Dashed line is best fit corresponding to the equation presented in the inset. B) Response of the PdNS sensor to varying concentrations of $\mathrm{H}_{2}$ at different temperatures $\left(-10\right.$ to $\left.80{ }^{\circ} \mathrm{C}\right)$, C) Zoomed in response of the PdNS sensor at low temperature $\left(10\right.$ and $\left.-10{ }^{\circ} \mathrm{C}\right)$. 
A

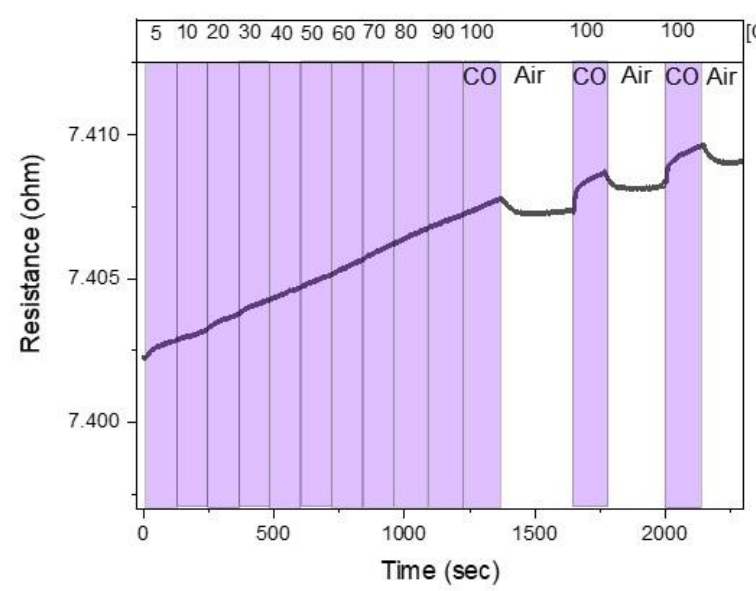

B

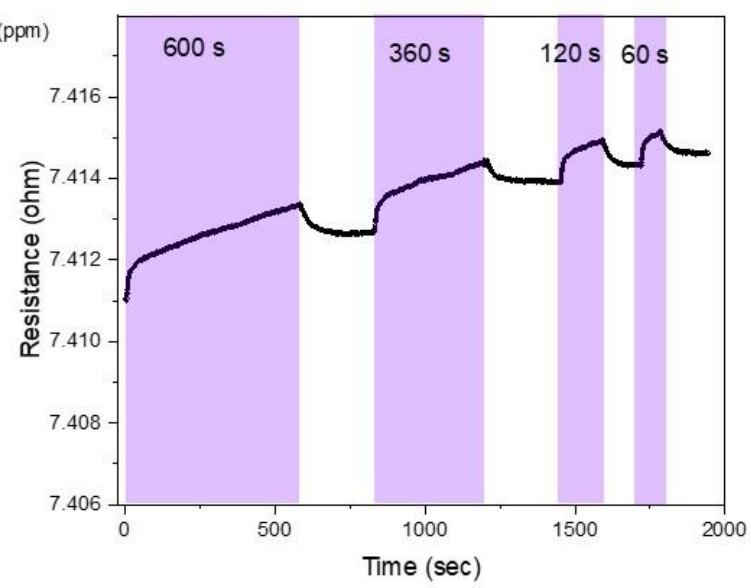

Figure 14: A) Response of the PdNS sensor to varying concentrations of CO (5-100 ppm) without air purge and with air purge; B) Response of the PdNS sensor to $100 \mathrm{ppm}$ of CO at varying time intervals 